\title{
The use of CAM providers and psychiatric outpatient services in people with anxiety/ depression: a cross-sectional survey
}

\author{
Anne Helen Hansen ${ }^{1,2^{*}}$ (D) and Agnete E. Kristoffersen ${ }^{3}$
}

\begin{abstract}
Background: Depression has been identified as one of the most frequent predictors of CAM use. However, limited data exist about the use of CAM providers among people with anxiety/depression in Norway. The aim of this study was to investigate the use of CAM providers, and the use of CAM providers and psychiatric outpatient services in combination, among people with self-reported anxiety and/or depression.

Methods: We used questionnaire data from 12,982 participants (30-87 years) in the cross-sectional sixth Troms $\varnothing$ Study (conducted in 2007-8). Eligible for analyses in our study were 1685 participants who reported suffering from anxiety and/or depression. By descriptive statistical methods, we estimated the use of CAM providers, psychiatric outpatient services, and the combination of these. By logistic regressions we studied the association between the use of these services and gender, age, income, education, and self-reported degree of anxiety/depression.

Results: During the previous year, $17.8 \%$ of people with anxiety/depression visited a CAM provider once or more, $11.8 \%$ visited psychiatric outpatient services, and $2.5 \%$ visited both. Men with anxiety/depression were less likely to visit CAM providers compared to women (odds ratio [OR] 0.40, confidence interval [CI] 0.30-0.55), whereas higher educated people were more likely to visit compared to the lowest educated (OR 1.47, Cl 1.02-2.13). The use of CAM providers was not associated with the degree of anxiety/depression. For those who used both CAM providers and psychiatric specialist services during the previous year, severe anxiety/depression was strongly associated with use compared to moderate disease (OR 7.53, Cl 2.75-20.65).
\end{abstract}

Conclusions: People with severe anxiety/depression seem to use CAM providers and psychiatric services additionally, whereas those with moderate disease seem to use these services more as alternative pathways. CAM provider treatment might be a substitute for conventional care, particularly in patients with moderate disease.

Keywords: Complementary and alternative medical providers, Psychiatric specialist services, Mental health care, Health care utilisation, Cross-sectional study, Norway

\section{Background}

Anxiety and depression are common mental disorders and global leading causes of all non-fatal burden of disease [1]. Nevertheless, around half of depressed persons worldwide do not receive treatment [2]. Most mental disorders emerge before the age of $30[3,4]$, and lack of treatment might contribute to disability for many crucial years of an individual's

\footnotetext{
* Correspondence: anne.helen.hanzen@gmail.com

${ }^{1}$ University Hospital of North Norway, PO box 35, 9038 Tromsø, Norway

${ }^{2}$ Faculty of Health Sciences, Department of Community Medicine, UiT-The

Arctic University of Norway, Troms $\varnothing$, Norway

Full list of author information is available at the end of the article
}

life. In Norway, the 12 months prevalence of anxiety and depression is around 15 and $10 \%$, respectively [5].

Anxiety and depression are identified as strong predictors for use of complementary and alternative medicine (CAM), and self-directed CAM modalities are more widely used than therapies requiring consultations with a CAM practitioner [6-8]. Although use of CAM among patients with anxiety and depression seems common, limited data exist about the use of CAM providers and the combined use of CAM providers and psychiatric outpatient services among people with anxiety/depression in Norway. 
In this study, CAM use is limited to the use of CAM providers and does not include the use of CAM techniques or products without CAM provider visits. Definitions of CAM providers vary between countries and organisations. In line with the Norwegian law about alternative treatment [9] we here define CAM providers as "providers others than authorized health personnel who give health-related treatment outside the established health services." CAM provider visits may encompass any conceivable CAM treatment, however, the most commonly used CAM providers offer massage, acupuncture, naprapathy, reflexology and spiritual healing [10]. Chiropractors are authorised health personnel in Norway [11], and thus not included as CAM providers in this study. The use of psychiatric outpatient services in this study is defined as visits to private and public providers, including visits to hospital staff like nurses and social workers, supervised by psychiatrists and psychologists.

The utilisation of CAM providers has increased in Europe in recent years [12]. Utilisation in Norway is higher among women than men and higher in younger/ middle ages $[13,14]$. Patients visit CAM providers due to a desire to achieve a more holistic view, active participation, and empowerment in care $[15,16]$, trust in CAM providers [15], distrust in traditional health care [17], and negative communication experiences with doctors [18].

All Norwegian citizens are provided a regular GP. The municipalities run first line medical services. Specialist services, consisting of hospitals and outpatient clinics, are run by regional health enterprises mainly owned by the state. Access to specialist care is usually achieved by referral from the GP (the gate-keeper role), however, waiting lists for psychiatric specialist consultations have been long.

Norway has universal insurance, and GP and specialist outpatient visits are co-payed by a small fee. CAM provider visits are fully paid by the users, and referral from the GP is not required.

Troms $\varnothing$ is the largest city in North Norway with around 72,000 inhabitants, and around 50 CAM providers (unpublished observation by AEK). The municipality is almost equal to Norway for key parameters like employment and unemployment, average gross income per capita, proportion of disability pensioners, number of physicians per 10,000 residents, and proportion of the population living in urban areas, whereas the population is younger and higher educated than the Norwegian average [19]. Tromsø hosts the University Hospital of North Norway with somatic and psychiatric services.

Our first study aim was to explore the level to which people with self-reported anxiety and/or depression use CAM providers, and to what extent CAM providers and psychiatric outpatient services are used separately or in combination. Secondly, we aimed to investigate whether the use of CAM providers, and the use of CAM providers and psychiatric outpatient services in combination, was associated with gender, age, education, income and selfrated degree of anxiety/depression.

\section{Methods \\ Study population}

Questionnaire data were retrieved from the cross-sectional sixth Tromsø Study (Tromsø 6), consisting of two comprehensive self-administered questionnaires, clinical examinations and laboratory tests, conducted from October 2007 to December 2008. Four groups were invited; every resident aged $40-42$ or $60-87$ years $(n=12,578)$, a $10 \%$ random sample of individuals aged $30-39(n=1056)$, a $40 \%$ random sample of people aged $43-59(n=5787)$ and all subjects who had attended the second visit of the fourth Tromsø Study, if not already included in the other three groups $(n=341)$.

The first questionnaire was mailed with the invitation about 2 weeks ahead of the suggested appointment time. Participants were invited to attend whenever suitable within the survey opening hours (between 09:00 and 18:00). Non-respondents were given one reminder. The second questionnaire was handed out at attendance, and most participants completed it while waiting for the clinical examination. The comprehensive Tromsø 6 data include self-reported demographic and socio-economic characteristics, information about symptoms and diseases, health status, and use of medicines and health services. Since residents with severe mental disorders are unlikely to participate in population-based surveys like Tromsø 6 [20] the study mainly includes persons with minor psychiatric morbidity.

Starting from the 12,982 participants, we first excluded those who reported no anxiety/depression $(n=9790)$, followed by participants who failed to inform about anxiety/depression $(n=1090)$, CAM visits $(n=208)$, and psychiatric outpatient visits $(n=209)$. The sample finally consisted of 1685 participants (Fig. 1).

\section{Measures}

The three dependent dichotomous variables were use of CAM providers, use of psychiatric outpatient services, and use of both these services in combination once or more during the previous year (yes/no). Independent variables were age in 20-year groups, education, income, and selfreported degree of anxiety/depression. We defined three education response categories from the original five: low (primary and part of secondary school), middle (high school) and high education (college or university). The income variable referred to the household's total gross income in the previous year. Eight original response categories were merged into low income (< NOK 200,000), low middle income (NOK 201,000-400,000), high middle income (NOK 


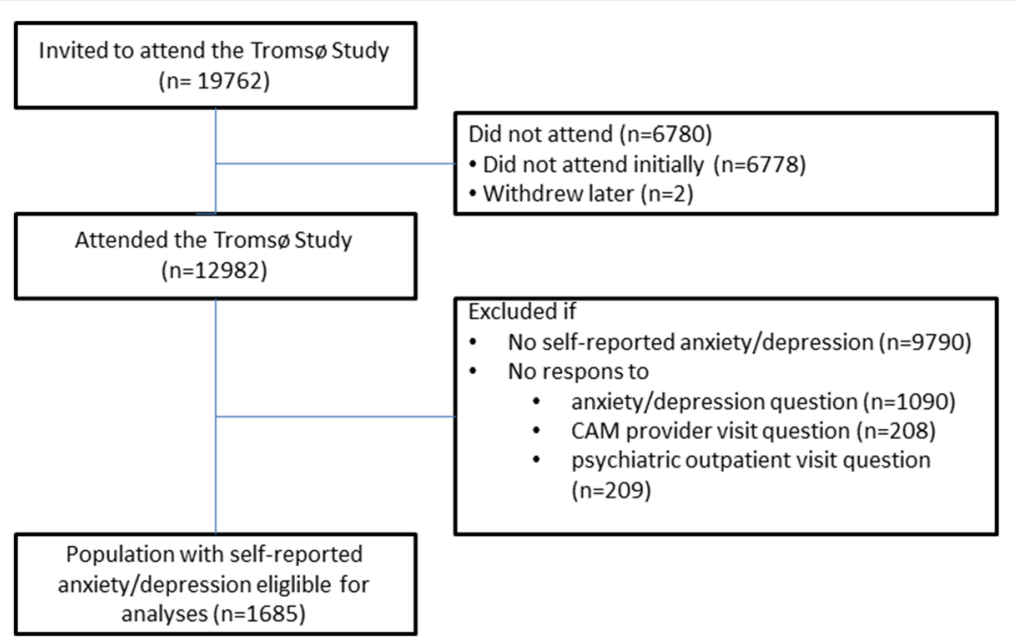

Fig. 1 Flow chart of study population

401,000-700,000) and high income (> NOK 700,000). Anxiety/depression was categorised moderate or severe.

\section{Analyses}

Data were analysed by means of descriptive statistics and logistic regressions. Correlations were tested with Spearman's correlation coefficients. We constructed three multivariable regression models, one for each of the dependent variables. Identical sets of independent variables were introduced collectively into the models.

We used $95 \%$ confidence intervals $(\mathrm{CI})$ as significance level throughout the study. All analyses were accomplished using Stata, version 14.0.

\section{Results}

In total 12,982 persons aged 30-87 years participated in Tromsø 6, constituting an overall response rate of $65.7 \%$. Eligible for analyses in our study were the 1685 persons who reported to suffer from anxiety and/or depression (Fig. 1). Women, persons aged 50-69 years, persons with high education, high middle income, and moderate anxiety/ depression made up the largest groups (Table 1). A moderate degree of self-reported anxiety/depression was far more common than a severe anxiety/depression (Table 1).

During the previous year, $17.8 \%$ of people with anxiety/depression visited a CAM provider once or more, $11.8 \%$ visited psychiatric outpatient services, and $2.5 \%$ visited both (Table 2 ).

Men with anxiety/depression visited CAM providers less likely than women (odds ratio [OR] 0.40, confidence interval [CI] 0.30-0.55), whereas higher educated people were more likely to visit than the lowest educated (OR 1.47, CI 1.02-2.13) (Table 3). The use of CAM providers was not associated with the degree of anxiety/depression (Table 3).

Regarding visits to psychiatric outpatient services there were no statistically significant gender differences, whereas the probability of visits were significantly reduced by higher age and household income (Table 3), and increased by higher education (OR 1.71, CI 1.08-2.71). The use of psychiatric outpatient services was strongly associated with a more severe anxiety/depression (OR 7.09, CI 3.51-14.34).

For those who used both CAM providers and psychiatric specialist services during the previous year, only a more severe degree of anxiety/depression was strongly associated with use (OR 7.53, CI 2.75-20.65) (Table 3).

Table 1 Sample characteristics (\%)

\begin{tabular}{llll}
\hline & Both genders & Women (64.4\%) & Men (35.6\%) \\
\hline Age & $n=1685$ & $n=1085$ & $n=600$ \\
$30-49$ & 33.6 & 31.6 & 37.2 \\
$50-69$ & 48.6 & 48.3 & 49.1 \\
$70-87$ & 17.8 & 20.1 & 13.7 \\
Education ${ }^{\text {a }}$ & $n=1659$ & $n=1072$ & $n=587$ \\
Low & 33.6 & 35.9 & 29.5 \\
Middle & 32.0 & 32.5 & 31.2 \\
High & 34.4 & 31.6 & 39.3 \\
Household income & $n=1563$ & $n=982$ & $n=581$ \\
Low & 17.7 & 21.5 & 11.2 \\
Low middle & 31.8 & 32.5 & 30.8 \\
High middle & 32.7 & 30.6 & 36.1 \\
High & 17.8 & 15.4 & 21.9 \\
Degree of anxiety/ & $n=1685$ & $n=1085$ & $n=600$ \\
depression & & & 98.0 \\
Moderate & 97.3 & 96.9 & 2.0 \\
Severe & 2.7 & 3.1 &
\end{tabular}

a Low (primary/part of secondary school), Middle (high school), High (college/university)

bLow ( $<200,000$ NOK), Low middle (201,000-400,000 NOK), High middle (401,000-700,000 NOK), High ( $>700,000$ NOK) 
Table 2 Proportion of patients with self-reported anxiety/depression visiting CAM providers, psychiatric outpatient services, or both, once or more during the previous year

\begin{tabular}{|c|c|c|c|c|c|c|}
\hline & \multicolumn{2}{|c|}{ CAM provider visits } & \multicolumn{2}{|c|}{ Psychiatric outpatient visits } & \multicolumn{2}{|c|}{ CAM provider and psychiatric outpatient visits } \\
\hline & $\mathrm{n} / \mathrm{N}$ & $\%$ & $\mathrm{n} / \mathrm{N}$ & $\%$ & $\mathrm{n} / \mathrm{N}$ & $\%$ \\
\hline Total sample & $300 / 1685$ & 17.8 & $199 / 1685$ & 11.8 & $42 / 1685$ & 2.5 \\
\hline \multicolumn{7}{|l|}{ Gender } \\
\hline Female & $234 / 1085$ & 21.6 & $140 / 1085$ & 12.9 & $31 / 1085$ & 2.9 \\
\hline Male & $66 / 600$ & 11.0 & $59 / 600$ & 9.8 & $11 / 600$ & 1.8 \\
\hline \multicolumn{7}{|l|}{ Age } \\
\hline $30-49$ & $108 / 566$ & 19.1 & $94 / 566$ & 16.6 & $18 / 566$ & 3.2 \\
\hline $50-69$ & $149 / 819$ & 18.2 & $79 / 819$ & 9.7 & $19 / 819$ & 2.3 \\
\hline $70-87$ & $43 / 300$ & 14.3 & $26 / 300$ & 8.7 & $5 / 300$ & 1.7 \\
\hline \multicolumn{7}{|l|}{ Education $^{a}$} \\
\hline Low & $81 / 558$ & 14.5 & $54 / 558$ & 9.7 & $9 / 558$ & 1.6 \\
\hline Middle & $101 / 531$ & 19.0 & $54 / 531$ & 10.2 & $12 / 531$ & 2.3 \\
\hline High & $115 / 570$ & 20.2 & $86 / 570$ & 15.1 & $21 / 570$ & 3.7 \\
\hline \multicolumn{7}{|c|}{ Household income $^{b}$} \\
\hline Low & $42 / 276$ & 15.2 & $40 / 276$ & 14.5 & $10 / 276$ & 3.6 \\
\hline Low middle & $87 / 498$ & 17.5 & $52 / 498$ & 10.4 & $12 / 498$ & 2.4 \\
\hline High middle & $108 / 511$ & 21.1 & $46 / 511$ & 9.0 & $9 / 511$ & 1.8 \\
\hline High & $48 / 278$ & 17.3 & $43 / 278$ & 15.5 & $10 / 278$ & 3.6 \\
\hline \multicolumn{7}{|c|}{ Degree of anxiety/depression } \\
\hline Moderate & 289/1639 & 17.6 & $178 / 1639$ & 10.9 & $36 / 1639$ & 2.2 \\
\hline Severe & $11 / 46$ & 23.9 & $21 / 46$ & 45.7 & $6 / 46$ & 13.0 \\
\hline
\end{tabular}

${ }^{a}$ Low (primary/part of secondary school), Middle (high school), High (college/university)

b Low (<200,000 NOK), Low middle (201,000-400,000 NOK), High middle (401,000-700,000 NOK), High (>700,000 NOK)

There were no strong correlations (defined as rho $>0.5$ ) between any of the independent variables in the models.

\section{Discussion}

\section{Key findings}

The main finding of the current study is that $17.8 \%$ of people with anxiety/depression visited a CAM provider once or more during a year, $11.8 \%$ visited psychiatric outpatient services, and $2.5 \%$ visited both. CAM providers were more likely visited by women and by people with higher education. The probability of visiting psychiatric services, and CAM providers and psychiatric services in combination, was strongly associated with more severe symptoms of anxiety/depression, whereas the separate use of CAM providers was not.

\section{CAM provider visits}

The CAM provider visit rate of $17.8 \%$ in the current study is not far from a US study (data from 1997 to 98) where $20 \%$ of those with anxiety attacks had visited a CAM provider within the last 12 months [7]. However, our CAM visit rate of $23.9 \%$ among those with severe disease is somewhat higher than the $19.3 \%$ visit rate among patients with severe depression [7]. Another US study (data from 1996) reported that only $9.8 \%$ of those with a mental condition had visited a CAM practitioner [6], whereas an Australian study (data collected in 200708) found that $41.8 \%$ of those with a chronic mental health condition had visited a CAM provider during the previous year [8]. The lower rates in the studies from the 90s conform with the general increased use of CAM providers during the period up to our survey [12]. In addition, a plausible explanation of the difference in visit rates is the inter study variation of definitions and methodology, for instance the inclusion or exclusion of chiropractors as CAM practitioners $[6-8,21]$. Differences in availability and access to CAM providers, conventional psychiatric care, and other sources of mental care in different countries, geographical contexts, and health care systems might also influence the differences in CAM visit rates [22].

We found a higher use of CAM providers among people with anxiety/depression than among the general Tromsø population (12.7 \%) [13], a pattern also observed in other populations [23]. Possible explanations might be easier access and less stigma when visiting CAM providers compared to conventional care [24, 25], the 
Table 3 Probability of visiting CAM providers, psychiatric outpatient services, or both once or more during the previous year in a population with self-reported anxiety/depression (multivariable logistic regressions)

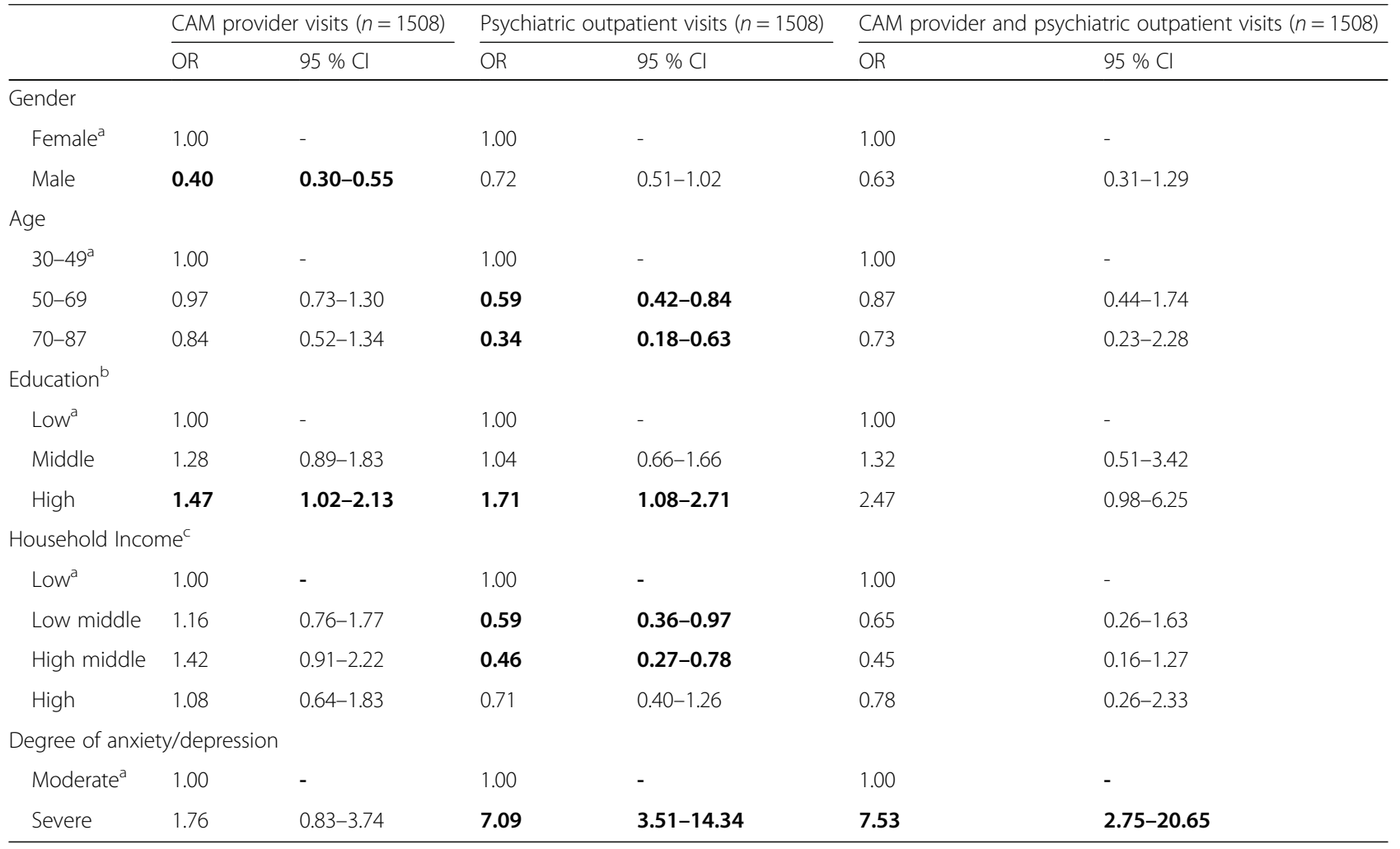

$O R$ odds ratio, $\mathrm{Cl}$ confidence interval

${ }^{\text {a }}$ Reference groups

b Low (primary/part of secondary school), Middle (high school), High (college/university)

'Low (<200,000 NOK), Low middle (201,000-400,000 NOK), High middle (401,000-700,000 NOK), High (>700,000 NOK)

Statistically significant findings are marked in bold

holistic perspective and active patient participation offered by CAM therapists $[15,16]$, and the higher somatic morbidity among people with mental health problems [26].

\section{Combined CAM provider and psychiatric specialist visits}

Most CAM therapy use seem to be concurrent to the use of conventional treatment [7, 23, 27]. In the present study, only $2.5 \%$ reported visits to both CAM providers and psychiatric services during the previous year. This is a notably low rate compared to the finding by Simon et al that CAM providers were aware of concurrent conventional care for mental health problems in $20-50 \%$ of visits [21]. However, we studied the combination of CAM provider and conventional specialist care, whereas Simon et al also included conventional primary care. Despite these methodological differences, our low rate probably reflects a low access to psychiatric specialist care in Tromsø, Norway, as reported elsewhere [28]. In addition, the low rate might be related to stigma, leading people not to seek care in specialist psychiatric settings [29, 30]. Another possible explanation is that some people with anxiety/depression might be satisfied with care from one provider, whether care is offered by a CAM provider or a mental care specialist.

\section{Use according to gender and education}

In the present study, men with anxiety/depression used CAM providers significantly less than women, which is in line with others' findings [23]. Low use among men might be explained by preconceptions of masculine behaviour in a traditional sense, hindering men from showing their need for help and support [31]. Another explanation is related to the idea that men perceive their body and health as more "mechanical" than women, and that they, therefore, are less attracted to CAM where wholeness, communication and personal relations are more pronounced than biological mechanisms [32].

Overall, it is reported that CAM therapy users with depressive disorders have a higher level of education than non-users [23]. In line with this, we found that higher educated people more likely visited CAM providers. However, this contrasts findings of no such association in general populations in Norway [14, 33, 34], but conforms with most international studies [35]. It is believed that higher education increases the perception of mental problems and the willingness to seek care [28]. People with higher education might also be more able to find relevant information about CAM, and to afford such treatment [36]. 
There were no statistically significant associations between gender and education on the one hand, and the combined use of CAM providers and psychiatric specialist services on the other. This confirms with our previous study regarding use of psychiatric specialist services among people with anxiety/depression [28].

The current findings regarding age and household income are discussed elsewhere [14, 28].

\section{Use according to severity of disease}

People with moderate anxiety/depression used CAM providers more than they used psychiatric specialists, whereas we found the opposite regarding people with severe disease. Still, less than half of those with severe anxiety/depression visited psychiatric specialist services during a year. Results regarding visits to psychiatric specialist services are discussed elsewhere [28].

In the group with severe anxiety/depression, $13 \%$ visited both a CAM provider and psychiatric specialist services, and the probability of visiting was 7.53 times higher than among those with moderate disease. The severe sufferers thus seem to use CAM providers and conventional care additionally. The higher use of both services in patients reporting more severe depression is in line with Adams et al [37], but in contrast to Druss et al who found no difference regarding the degree of mental health problems [6].

Only $2.2 \%$ of those reporting moderate anxiety/depression used combined care. This might be due to the overall lower use of both CAM and conventional care in the current study. Other reasons could be that people with moderate disease would avoid seeking help from conventional psychiatric services due to fear of stigma and feelings of guilt and shame [38], and also that CAM providers might be a substitute or an alternative pathway when access to conventional care is limited $[39,40]$. On the other hand, those who report moderate ailments might be satisfied with CAM provider treatment alone. The line between prevention and treatment might be intertwined in many of these cases. A low threshold CAM service could be a proper supplement for some with minor morbidity, seeking to prevent worsening of symptoms.

Summing up, one might say that psychiatric specialist services seems to be reserved for those with the most severe disease, in keeping with the guidelines that specialist care should treat the sickest, and that moderate ailments to a greater extent are treated elsewhere. However, our findings add to a solid documentation that the use of mental health services both in general populations and in people with anxiety/depression in high income countries is limited, indicating that these symptoms are undertreated [2, 41, 42].

\section{Strengths and limitations}

Particular strengths of this study were the large sample size, the high response rate, and the comprehensive coverage of information about health, disease, and socio-economic status in the questionnaires.

Nevertheless, the study should be interpreted in light of some limitations. Despite a high baseline response rate, our sample may not be entirely representative of the population suffering from anxiety/depression, as it is well known that women, healthier persons, and higher socioeconomic groups are more likely to participate in population surveys [43]. In Tromsø 6, attendees were older, and the proportion women were higher than in non-attendees $[44,45]$. In the second Tromsø Study (1979-80) the participation of people with psychiatric morbidity was approximately $20 \%$ lower than for those without such morbidity [20], and lower participation is likely the case for Tromsø 6 as well. However, this applies particularly to serious psychiatric morbidity $[20,46]$.

Additionally, our data might underestimate psychiatric morbidity and treatment seeking due to perceived stigma [29], and treatment seeking might also be underestimated in the population since questions about psychiatric conditions and use of services were spread throughout the questionnaire, probably increasing inaccuracies [47]. However, there is hardly any reason why people should report anxiety/depression but not use of CAM providers and psychiatric services, thus the relative validity between these variables should be quite robust.

The validity of self-reported data as such may be questioned, although agreement between self-reported and registered health care utilisation is generally high [48]. It might also be easier to report anxiety/depression in a self-administered questionnaire than reporting to health care providers. Moreover, self-reported anxiety/depression might be the best available measure for our study purpose, since research based on doctor made diagnoses would make it difficult to include the non-visitors.

Our analyses focused on anxiety/depression, but we cannot rule out the possibility that participants may have had other psychiatric and/or somatic ailments or diseases in addition, because the reasons for visiting were not reported.

Furthermore, it might be a problem that we asked about anxiety/depression at the time of the survey, whereas health care utilisation was reported for the previous 12 months. However, the onset of these diseases is often ahead of 30 years of age [3, 4], making it unlikely that this have affected our study.

Finally, we cannot exclude the possibility of unmeasured confounders of the reported associations.

\section{Conclusions}

During a year, around $17.8 \%$ of people with anxiety/depression visited a CAM provider whereas only $2.5 \%$ visited CAM providers and psychiatric services in combination. People with severe disease seem to use CAM providers and psychiatric services additionally, whereas 
those with moderate disease seem to use these services as alternative pathways. Our results indicate that the most severe sufferers use psychiatric specialist services more than those with moderate disease, and that CAM provider treatment might be a substitute for conventional care, particularly in patients with moderate disease. We suggest treatment outcome and efficacy in the different contexts to be an important direction for future research.

\section{Abbreviations}

CAM: Complementary and alternative medicine; $\mathrm{Cl}$ : Confidence interval; GP: General practitioner; NOK: Norwegian Kroner; OR: Odds ratio; Troms $\varnothing$ 6: The sixth Tromsø study

\section{Acknowledgements}

We thank the people of Troms $\varnothing$ and the Troms $\varnothing$ Study for giving data to this study. We also thank The University Hospital of North Norway, and UiT - The Arctic University of Norway, who funded this research.

\section{Funding}

The University Hospital of Northern Norway and UiT - The Arctic University of Norway funded this research.

\section{Availability of data and materials}

The raw dataset is not available due to Norwegian privacy regulations. Applicants for any data must be prepared to conform to Norwegian privacy regulations.

\section{Authors' contributions}

Both authors contributed to the design and conduct of the study. $\mathrm{AHH}$ did the statistical analyses and drafted the manuscript. Both authors contributed to the discussion of results, and to major improvements and critical revisions of the manuscript. Both authors approved the final version for publication.

\section{Authors' information}

BSW MD PhD project leader Anne Helen Hansen is a specialist in Family Medicine and Community Medicine. Since 2010 she has been involved in different health care services research projects and relevant papers. She is employed by the University Hospital of North Norway, and affiliated to the Department of Community Medicine, UiT- The Arctic University of Norway. MA PhD Agnete Egilsdatter Kristoffersen, is a senior researcher at The National Research Center in Complementary and Alternative Medicine (NAFKAM), Department of Community Medicine, UiT- The Arctic University of Norway. Since 2002 she has conducted research in the area of Complementary and Alternative Medicine (CAM) with a special focus on prevalence and association for CAM use in different patient groups.

\section{Competing interests}

The authors declare that they have no competing interests.

\section{Consent for publication}

Not applicable.

\section{Ethics approval and consent to participate}

Tromsø 6 has been approved by the Regional Committee for Medical and Health Research Ethics (REK 2009/2536). Written informed consent was obtained from all participants.

Permission to access data from the Tromsø Study was given 27.04.2014 (Project No. 7730.00012).

\section{Author details}

${ }^{1}$ University Hospital of North Norway, PO box 35, 9038 Tromsø, Norway. ${ }^{2}$ Faculty of Health Sciences, Department of Community Medicine, UiT-The Arctic University of Norway, Tromsø, Norway. ${ }^{3}$ The National Research Center in Complementary and Alternative Medicine (NAFKAM), Faculty of Health Sciences, Department of Community Medicine, UiT-The Arctic University of Norway, Tromsø, Norway.
Received: 21 April 2016 Accepted: 3 November 2016

Published online: 11 November 2016

\section{References}

1. Whiteford HA, Degenhardt L, Rehm J, Baxter AJ, Ferrari AJ, Erskine HE, Charlson FJ, Norman RE, Flaxman AD, Johns N, et al. Global burden of disease attributable to mental and substance use disorders: findings from the Global Burden of Disease Study 2010. Lancet. 2013;382(9904):1575-86.

2. Wang PS, Aguilar-Gaxiola S, Alonso J, Angermeyer MC, Borges G, Bromet EJ, Bruffaerts R, de Girolamo G, de Graaf R, Gureje O, et al. Use of mental health services for anxiety, mood, and substance disorders in 17 countries in the WHO world mental health surveys. Lancet. 2007;370(9590):841-50.

3. Kessler RC, Berglund P, Demler O, Jin R, Merikangas KR, Walters EE. Lifetime prevalence and age-of-onset distributions of DSM-IV disorders in the National Comorbidity Survey Replication. Arch Gen Psychiatry. 2005;62(6):593-602.

4. Eisenberg D, Golberstein E, Gollust SE. Help-seeking and access to mental health care in a university student population. Med Care. 2007;45(7):594-601.

5. Mykletun A, Knudsen AK, Mathiesen KS. Psykiske lidelser i Norge: Et folkehelseperspektiv. Nasjonalt Folkehelseinstitutt. Rapport 2009:8 (Mental disorders in Norway: A public health perspective. Norwegian Institute of Public Health. Report 2009:8). 2009. (in Norwegian).

6. Druss BG, Rosenheck RA. Use of practitioner-based complementary therapies by persons reporting mental conditions in the United States. Arch Gen Psychiatry. 2000;57(7):708-14.

7. Kessler RC, Soukup J, Davis RB, Foster DF, Wilkey SA, Van Rompay MI, Eisenberg $\mathrm{DM}$. The use of complementary and alternative therapies to treat anxiety and depression in the United States. Am J Psychiatry. 2001;158(2):289-94.

8. Spinks J, Hollingsworth B. Policy implications of complementary and alternative medicine use in Australia: data from the National Health Survey. J Altern Complement Med. 2012;18(4):371-8.

9. Law on alternative treatment of disease, etc. ACT-2003-06-27-64. vol. §2 2003. [https://lovdata.no/dokument/NL/lov/2003-06-27-64?q=lov_om_ alternativ behandling] (in Norwegian). Accessed 7 Nov 2016.

10. The NAFKAM Study. Use of complementary and alternative medicine in Norway. 2014. [http://nifab.no/hva_er_alternativ_behandling/tall_og_fakta/ nafkam_undersoekelsen_2014] (in Norwegian). Accessed 7 Nov 2016.

11. Health Personnel Act. ACT-1999-07-02-64. vol. §48; 1999. [https://lovdata.no/ dokument/NL/lov/1999-07-02-64?q=helsepersonelloven] (in Norwegian). Accessed 7 Nov 2016.

12. Fischer FH, Lewith G, Witt CM, Linde K, von Ammon K, Cardini F, Falkenberg $\mathrm{T}$, Fonnebo $\mathrm{V}$, Johannessen $\mathrm{H}$, Reiter $\mathrm{B}$, et al. High prevalence but limited evidence in complementary and alternative medicine: guidelines for future research. BMC Complement Altern Med. 2014;14:46.

13. Hansen $\mathrm{AH}$, Halvorsen PA, Forde $\mathrm{OH}$. The ecology of medical care in Norway: wide use of general practitioners may not necessarily keep patients out of hospitals. J Public Health Res. 2012;1:e28.

14. Hansen A, Kristoffersen AE, Lian OS, Halvorsen PA. Continuity of GP care is associated with lower use of complementary and alternative medical providers: a population-based cross-sectional survey. BMC Health Serv Res. 2014;14(1):629.

15. D'Crus A, Wilkinson JM. Reasons for choosing and complying with complementary health care: an in-house study on a South Australian clinic. J Altern Complement Med. 2005;11(6):1107-12.

16. Murray J, Shepherd S. Alternative or additional medicine? An exploratory study in general practice. Sos Sci Med. 1993;37(8):983-8.

17. Furnham A, Bhagrath R. A comparison of health beliefs and behaviours of clients of orthodox and complementary medicine. Brit J Clin Psychol. 1993; 32(Pt 2):237-46

18. Salamonsen A. Doctor-patient communication and cancer patients' choice of alternative therapies as supplement or alternative to conventional care. Scand J Caring Sci. 2013;27(1):70-6.

19. Facts about Tromsø Municipality. [http://www.tromso.kommune.no/fakta-omtromsoe-kommune.241052.no.html] (in Norwegian). Accessed 7 Nov 2016.

20. Hansen V, Jacobsen BK, Arnesen E. Prevalence of serious psychiatric morbidity in attenders and nonattenders to a health survey of a general population : the Tromso Health Study. Am J Epidemiol. 2001;154(10):891-4.

21. Simon GE, Cherkin DC, Sherman KJ, Eisenberg DM, Deyo RA, Davis RB. Mental health visits to complementary and alternative medicine providers. Gen Hosp Psychiatry. 2004;26(3):171-7.

22. Sirois FM, Purc-Stephenson RJ. When one door closes, another door opens: physician availability and motivations to consult complementary and alternative medicine providers. Complement Ther Clin Pract. 2008;14(4):228-36. 
23. Solomon D, Adams J. The use of complementary and alternative medicine in adults with depressive disorders. A critical integrative review. J Affect Disord. 2015;179:101-13.

24. Kiil MA. The paradox of home: understanding Noorthern Troms as a therapeutic landscape. In: Miller BH, editor. Idioms of sami health and healing patterns of Northern tradistional healing. Alberta: University of Alberta Press; 2015. p. 131-56.

25. Kiil MA. A room with a view: Navigating continuity and rupture within the traditional healing repertoire of Northern Troms. In: Naskali P, Seppänen M Bergum S, editors. Arctic change and elderly exclusion: an interdiciplinary analysis. London: Routledge; 2016. p. 231-47.

26. Bobo WV, Yawn BP, St Sauver JL, Grossardt BR, Boyd CM, Rocca WA Prevalence of Combined Somatic and Mental Health Multimorbidity: Patterns by Age, Sex, and Race/Ethnicity. J Gerontol A Biol Sci Med Sci. 2016. Epub ahead of print.

27. Unutzer J, Klap R, Sturm R, Young AS, Marmon T, Shatkin J, Wells KB. Mental disorders and the use of alternative medicine: results from a national survey. Am J Psychiatry. 2000;157(11):1851-7.

28. Hansen AH, Hoye A. Gender differences in the use of psychiatric outpatient specialist services in Tromso, Norway are dependent on age: a populationbased cross-sectional survey. BMC Health Serv Res. 2015;15:477.

29. Klap R, Unroe KT, Unutzer J. Caring for mental illness in the United States: a focus on older adults. Am J Geriatr Psychiatry. 2003;11(5):517-24.

30. Pattyn E, Verhaeghe M, Bracke $P$. The gender gap in mental health service use. Soc Psychiatry Psychiatr Epidemiol. 2015;50:1089-95.

31. Courtenay WH. Constructions of masculinity and their influence on men's wellbeing: a theory of gender and health. Soc Sci Med. 2000;50(10):1385-401.

32. Schei B, Bakketeig LS. Kvinner lider - menn dør: Folkehelse i et kjønnsperspektiv (Women suffer - men die: Public health from a gender perspective). Gyldendal akademisk: Oslo; 2007 (in Norwegian).

33. Steinsbekk A, Rise MB, Aickin M. Cross-cultural comparison of visitors to CAM practitioners in the United States and Norway. J Altern Complement Med. 2009;15(11):1201-7.

34. Steinsbekk A, Rise MB, Johnsen R. Changes among male and female visitors to practitioners of complementary and alternative medicine in a large adult Norwegian population from 1997 to 2008 (The HUNT studies). BMC Complement Altern Med. 2011;11:61.

35. Bishop FL, Lewith GT. Who uses CAM? A narrative review of demographic characteristics and health factors associated with CAM use. Evid Based Complement Alternat Med. 2010;7(1):11-28.

36. Kristoffersen AE, Stub T, Salamonsen A, Musial F, Hamberg K. Gender differences in prevalence and associations for use of CAM in a large population study. BMC Complement Altern Med. 2014;14:463.

37. Adams J, Sibbritt D, Lui CW. Health service use among persons with selfreported depression: a longitudinal analysis of 7,164 women. Arch Psychiatr Nurs. 2012;26(3):181-91.

38. Schomerus $\mathrm{G}$, Matschinger $H$, Angermeyer MC. The stigma of psychiatric treatment and help-seeking intentions for depression. Eur Arch Psychiatry Clin Neurosci. 2009;259(5):298-306.

39. Bazargan M, Ani CO, Hindman DW, Bazargan-Hejazi S, Baker RS, Bell D, Rodriquez M. Correlates of complementary and alternative medicine utilization in depressed, underserved african american and Hispanic patients in primary care settings. J Altern Complement Med. 2008;14(5):537-44.

40. Jorm AF, Griffiths KM, Christensen H, Parslow RA, Rogers B. Actions taken to cope with depression at different levels of severity: a community survey. Psychol Med. 2004;34(2):293-9.

41. Alonso J, Angermeyer MC, Bernert S, Bruffaerts R, Brugha TS, Bryson $\mathrm{H}$, de Girolamo G, Graaf R, Demyttenaere K, Gasquet I, et al. Use of mental health services in Europe: results from the European Study of the Epidemiology of Mental Disorders (ESEMeD) project. Acta Psychiatr Scand Suppl. 2004;420:47-54.

42. Thornicroft G. Most people with mental illness are not treated. Lancet. 2007; 370(9590):807-8

43. Galea S, Tracy M. Participation rates in epidemiologic studies. Ann Epidemiol. 2007;17(9):643-53.

44. The Tromsø Study website. [http://en.uit.no/ansatte/organisasjon/ artikkel?p_document_id=104991\&p_dimension_id=88111\&p_menu= 42374]. Accessed 7 Nov 2016

45. Eggen AE, Mathiesen EB, Wilsgaard T, Jacobsen BK, Njolstad I. The sixth survey of the Tromso Study (Tromso 6) in 2007-08: collaborative research in the interface between clinical medicine and epidemiology: study objectives, design, data collection procedures, and attendance in a multipurpose population-based health survey. Scand J Public Health. 2013;41(1):65-80.

46. Knudsen AK, Hotopf M, Skogen JC, Overland S, Mykletun A. The health status of nonparticipants in a population-based health study: the Hordaland Health Study. Am J Epidemiol. 2010;172(11):1306-14.

47. Duan N, Alegria M, Canino G, McGuire TG, Takeuchi D. Survey conditioning in self-reported mental health service use: randomized comparison of alternative instrument formats. Health Serv Res. 2007;42(2):890-907.

48. Reijneveld SA, Stronks K. The validity of self-reported use of health care across socioeconomic strata: a comparison of survey and registration data. Int J Epidemiol. 2001;30(6):1407-14.

\section{Submit your next manuscript to BioMed Central and we will help you at every step:}

- We accept pre-submission inquiries

- Our selector tool helps you to find the most relevant journal

- We provide round the clock customer support

- Convenient online submission

- Thorough peer review

- Inclusion in PubMed and all major indexing services

- Maximum visibility for your research

Submit your manuscript at www.biomedcentral.com/submit
Biomed Central 